\title{
HEAT TRANSFER IN THE FILTRATION CONDITIONS IN HETEROGENEOUS BUILDING ENVELOPES
}

Igor YU. Shalagin, Nikolaj I. Kurilenko, Rustam R. Davlyatchin National Research Tomsk Polytechnic University, 634050

Tomsk, Russia

\begin{abstract}
This paper describes the experimental study of temperature modes of light walling. We have performed theoretical and experimental research of temperature fields Walling and modernized surveyed construction
\end{abstract}

\section{INTRODUCTION}

Claddings should protect buildings from the direct weather impact. These functions of building envelopes are important for creating of the indoor climate (with the microclimate conditioning systems) [1].

In winter cladding separates air with different temperatures and usually with different barometric pressures [2]. The main efficiency measure of the building envelopes from the thermo-technical part is the thermal resistance. Thermal resistance depends on many factors - material density, humidity, air permeability, etc.

Today, a new kind of individual house building is heavily used in our country - a frame-panel technology. This technology provides significant savings in labor inputs (manufacturing of joints and building installation), reduction of construction time, building proper weight reduction, as well structures transportation costs.

Building envelopes in this type of construction no longer bear the load, and therefore become less massive. For building such constructions highly-porous insulants of lower thermal conductivity are used now, which turned out to be of higher air permeability as well. To study the efficiency of applied building envelopes constructed in accordance with frame-panel technology, field surveys were conducted on one of the newly constructed country houses.

\section{EXPERIMENTAL SETUP AND PROCEDURE}

The object of study has the following construction of the outer wall (Figure 1). Wooden posts (pine) with $50 \times 150 \mathrm{~mm}$ section settled $600 \mathrm{~mm}$ apart. Between the uprights there are horizontal wooden bars (pine) with the $50 \mathrm{x} 150 \mathrm{~mm}$ section. The span between the uprights is stacked with 3 layers of mineral wool with density of $50 \mathrm{~kg} / \mathrm{m}^{3}$, thickness of $50 \mathrm{~mm}$ and thermal conductivity coefficient of $0.039 \mathrm{~W} / \mathrm{m}{ }^{\circ} \mathrm{C}$. Usually, the checkerboard placement is applied to eliminate through joints. From the inside insulants are closed with the vapor barrier of "Izospan B" brand. The sheets of oriented strand board (OSB) are attached to the studs above the vapor barrier using the self-driving screws. The sheets thickness is of $9.5 \mathrm{~mm}$ and thermal conductivity of 0.15 $\mathrm{W} / \mathrm{m}{ }^{\circ} \mathrm{C}$. The joints between the gypsum boards are filled with spackling paste. On the outside, the insulant is closed with the OSB-sheets. OSB-sheets are covered with a housewrap of "Izospan A" brand. Over the housewrap and at the level of uprights, vertical wooden bars (pine) with the $50 \times 20 \mathrm{~mm}$ section are attached. Then vinyl siding is attached to those wooden bars. 


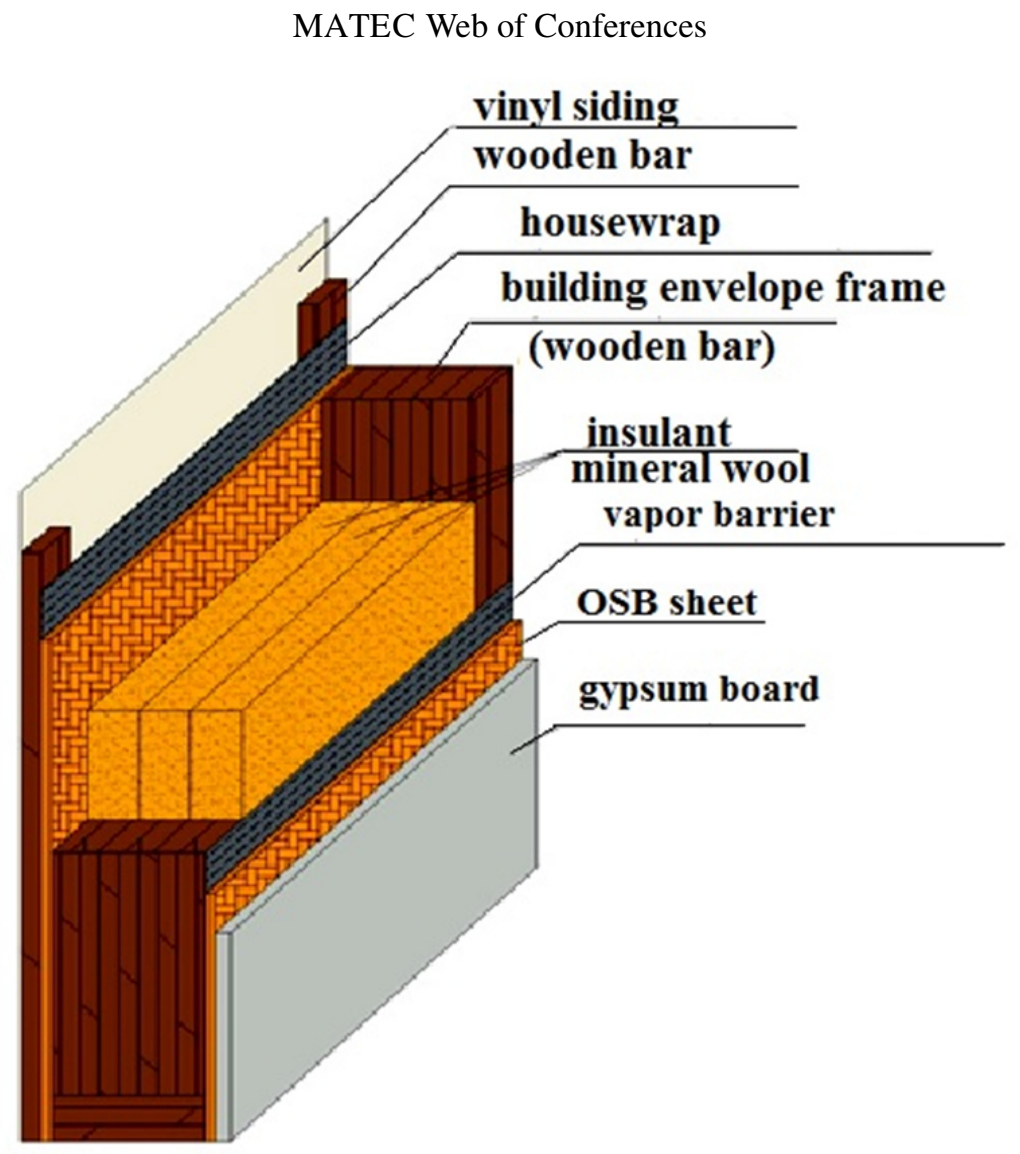

Figure 1. Wall construction fragment

To get the temperature fields on the internal surfaces of building envelopes, thermal vision survey systems were used [3]. The survey was carried out during the heating season, when the temperature of the internal air was $22,3{ }^{\circ} \mathrm{C}$ and the relative humidity was $24.2 \%$. Outside, air temperature at the time of the survey was $-8,6^{\circ} \mathrm{C}$. Figure 2 shows the temperature field of a wall construction fragment. 


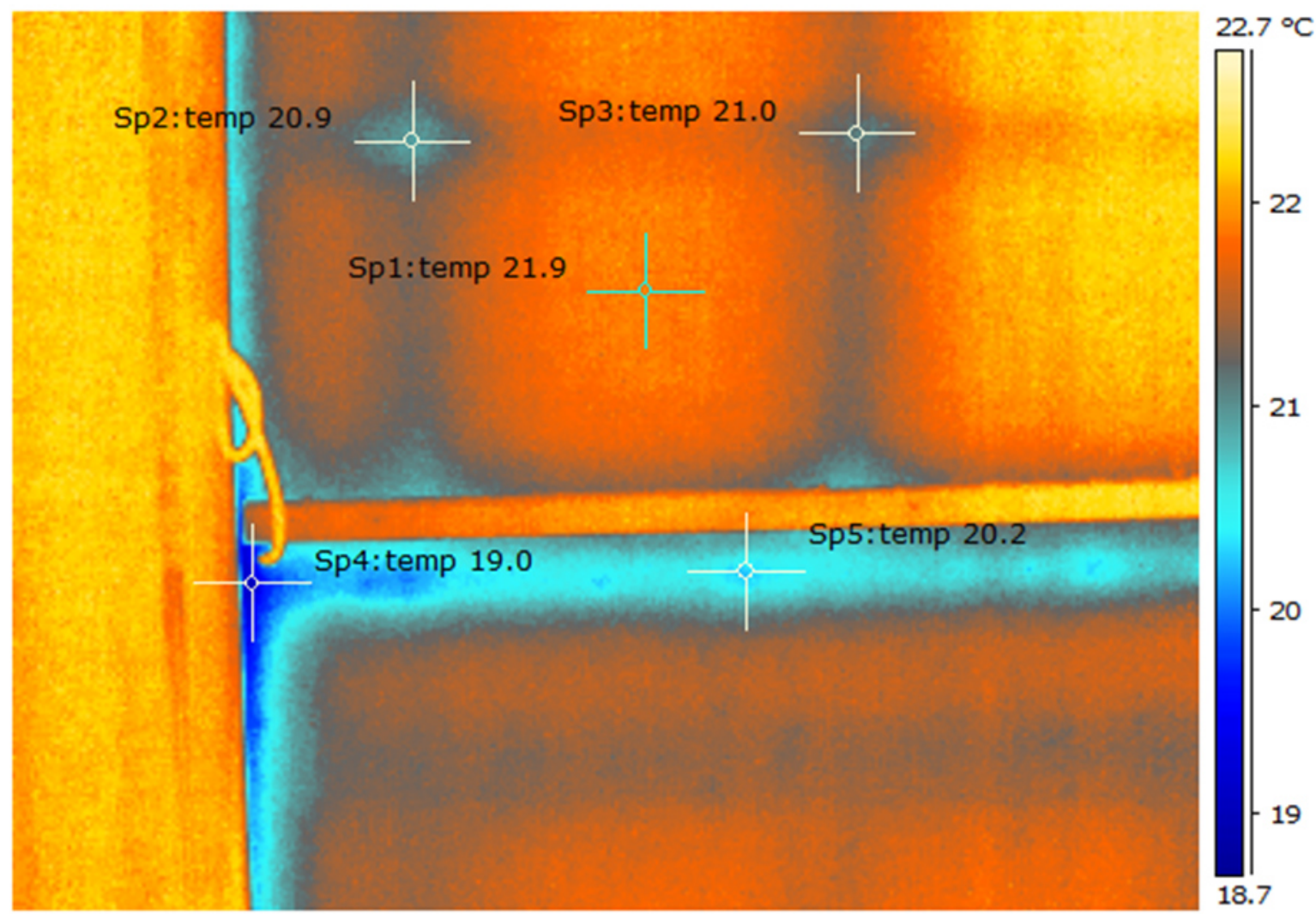

Figure 2. Temperature field of a wall fragment

As seen in Figure 2, in the locations of vertical and horizontal bars there are zones of low temperatures (up to $18,7^{\circ} \mathrm{C}$ ), which demonstrate the lower heat-shielding properties of a building envelope. Low temperature zones at the locations of the wooden bars arise from the fact that the bars material is in direct contact with the inner and outer surfaces of the building envelope. In other words, the wooden bars act as thermal (cold) bridges with width of $50 \mathrm{~mm}$. Such temperature conditions of the building envelopes meets the requirements [4] by the condition of the maximum differential $\left(4^{\circ} \mathrm{C}\right)$ between the temperature of the inside air $\left(22,3^{\circ} \mathrm{C}\right)$ and the inner wall surface $\left(19^{\circ} \mathrm{C}\right)$. It should be noted that according to [4] in the calculation of characteristic thermal resistance one takes an average outdoor temperature for the period, with an average daily temperature of not more than 8 ${ }^{\circ} \mathrm{C}$, which for Tyumen equals to $-7,2^{\circ} \mathrm{C}$.

\section{Results and discussion}

For comparison of the actual temperature distribution fields, calculation of this construction was performed with the help of "Elcut 6.1" program. During the calculations, the thermal conductivity of the wood material was taken as $0.457 \mathrm{~W} / \mathrm{m}{ }^{\circ} \mathrm{C}$ at a humidity of wood material not more than $30 \%$. It should be taken into account that the field survey was carried out after a short time after the construction of the building. Figure 3 presents the calculated fields of temperature distribution. 


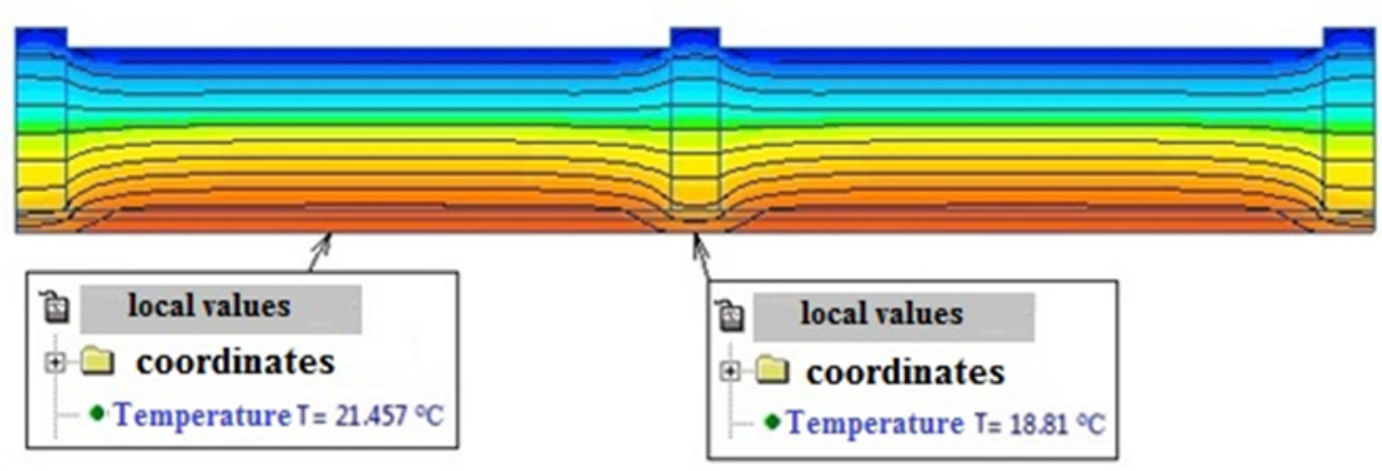

Temperature

$T{ }^{\circ} \mathrm{C}$
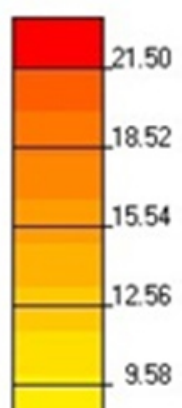

9.58

6.61

Figure 3. Temperature fields at the section of a wall

Comparative analysis of Figures 2 and 3 showed a high convergence of calculated and experimental values. The values of calculated temperatures at the inner surface of the building envelope were obtained when the outdoor air temperature was $-8,6^{\circ} \mathrm{C}$ and indoor air temperature equaled $22,3^{\circ} \mathrm{C}$. When testing the building envelope for compliance with the rated temperature differential between the temperature of the indoor air temperature and wall internal surface temperature, one should pay attention, that this differential [4] is not determined at the average outdoor air temperature (period with the daily average temperature less than $8^{\circ} \mathrm{C}$ ), but is determined at the average outdoor air temperature at the most cold five-day period with probability 0,92 . The temperature of the most cold five-day period in Tyumen is $-38^{\circ} \mathrm{C}$. Taking into account this fact, we recalculated the lowest temperature of cinstruction internal surface in accordance with the formula (2) app.7 [5] considering the calculated outdoor temperature $-38^{\circ} \mathrm{C}$, indoor $20^{\circ} \mathrm{C}$ and calculation of temperature fields distribution on the section of the building envelope. Calculated temperature of the internal surface receives from the formula (2) was $13,45^{\circ} \mathrm{C}$. Figure 4 presents the calculated fields of temperatures distribution at the outdoor temperature of -38 . 


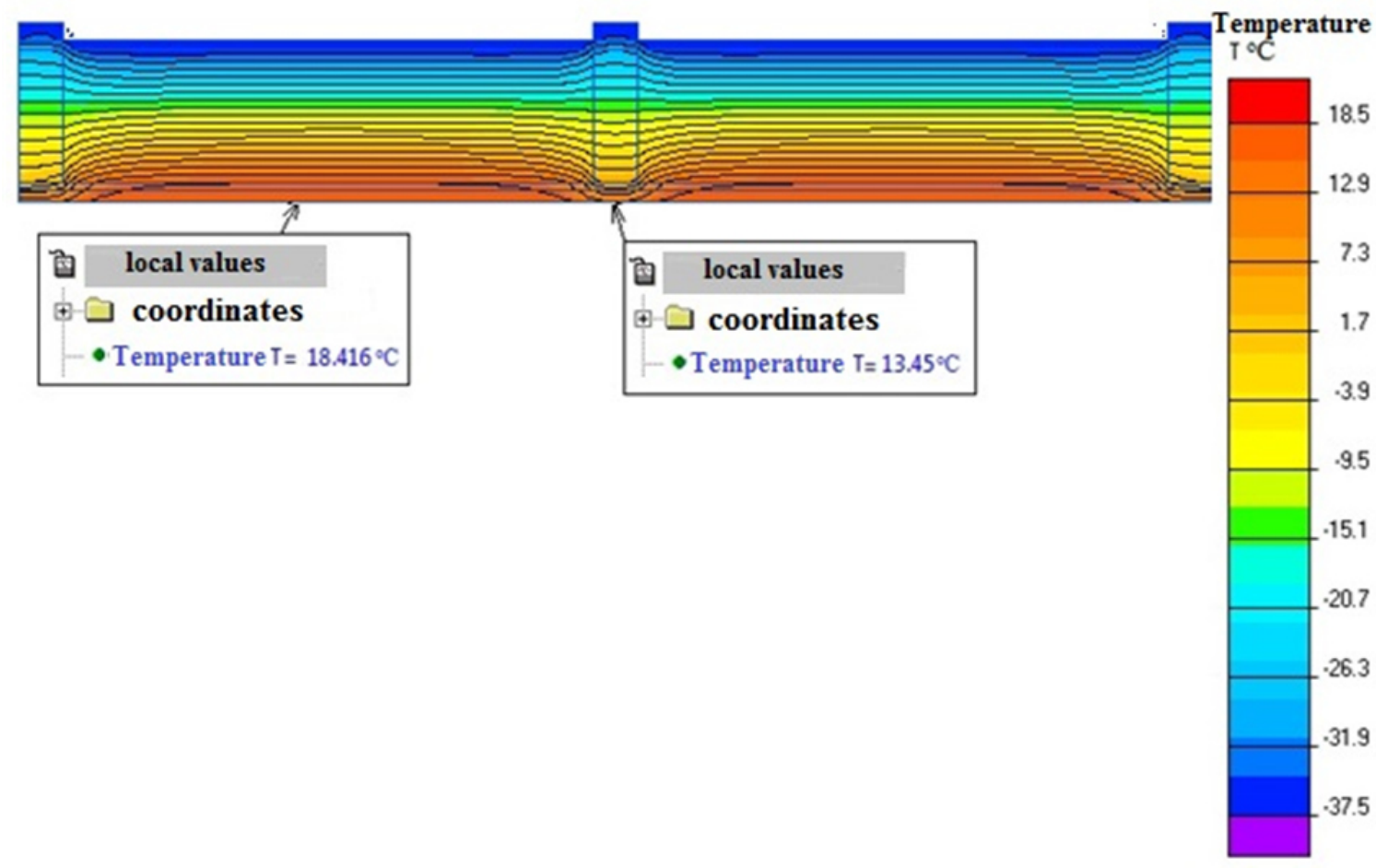

Figure 4. Temperatures fields at the section of the wall

As it is seen from the Figure 4, temperature values of construction internal surface near the vertical uprights converge with the temperature values received from the formula (2). The analysis of internal surface temperatures calculated in conditions of outdoor temperature during the coldest 5-day period showed, that the constructions temperature will not meet the regulation values [4] because of the exceeding temperature differential $\left(7^{\circ} \mathrm{C}\right)$ between the indoor air and internal wall surface. Within the further use of the building, volume humidity conditions for Tyumen will not exceed $12 \%$ as a result of the timber drying. According to [6] in case of $12 \%$ volume humidity and material average density (Scotch pine) of $600 \mathrm{~kg} / \mathrm{m}^{3}$ at negative temperatures, the thermal conductivity will be $0.292 \mathrm{~W} / \mathrm{m}{ }^{\circ} \mathrm{C}$. Figure 5 presents the calculated temperature distribution fields with the wood thermal conductivity of $0.292 \mathrm{~W} / \mathrm{m}{ }^{\circ} \mathrm{C}$.
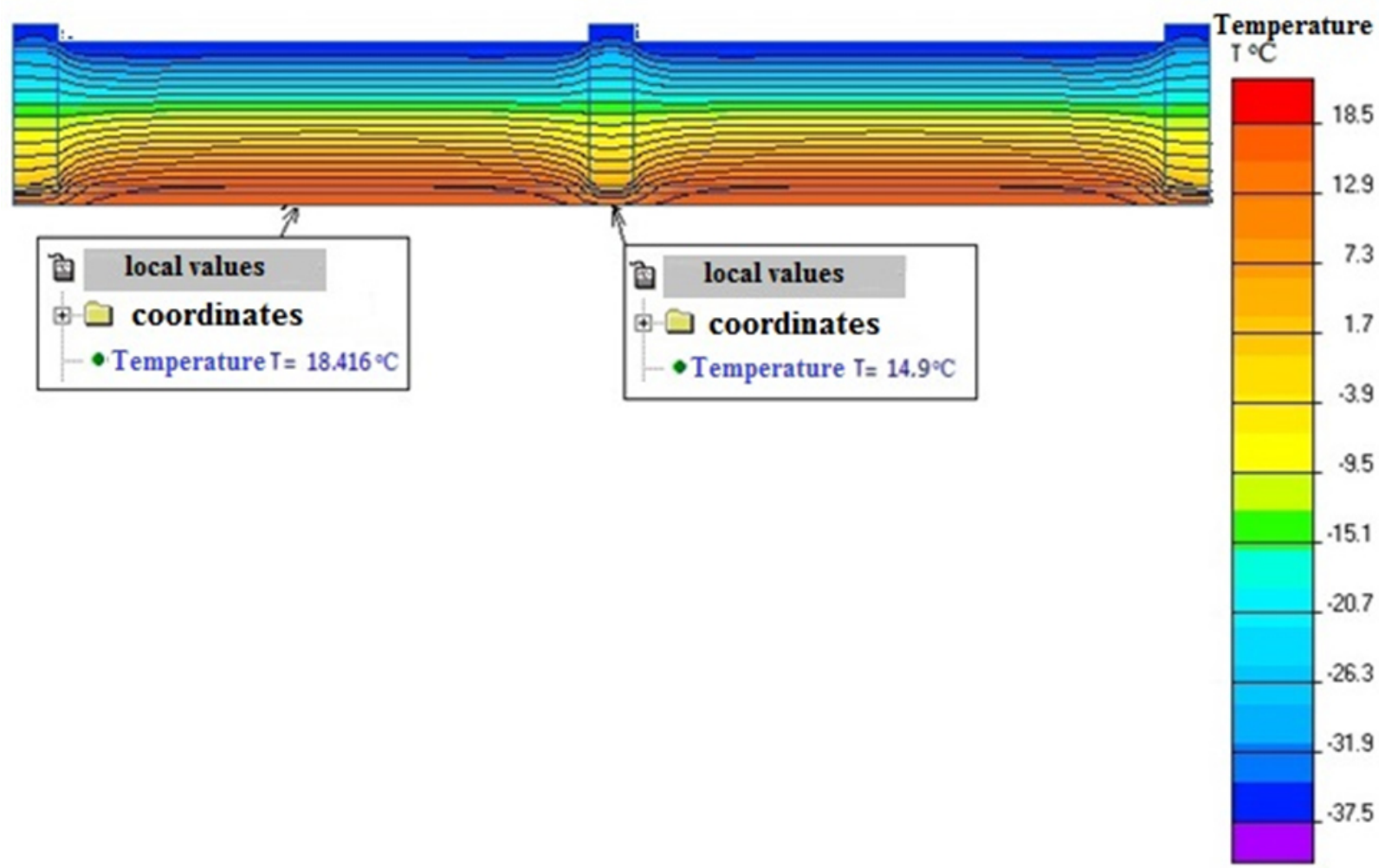

Figure 5. Temperature fields at the section of the wall 
The resulted of the conducted survey was the decision to optimize the construction of such building envelopes. Table 1 and Figure 6 present the calculation results of different construction types.

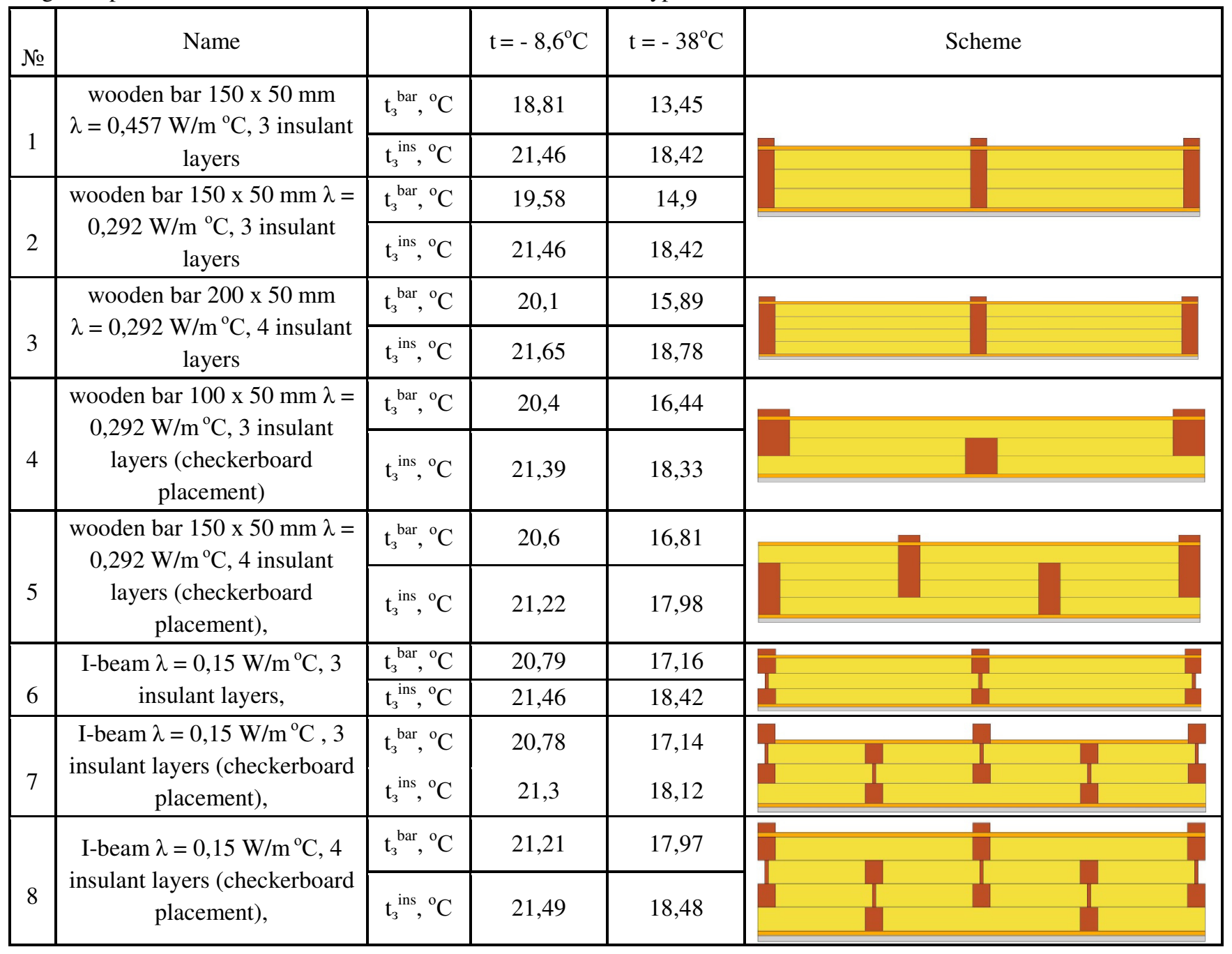

Table 1. Calculation results of different construction types 


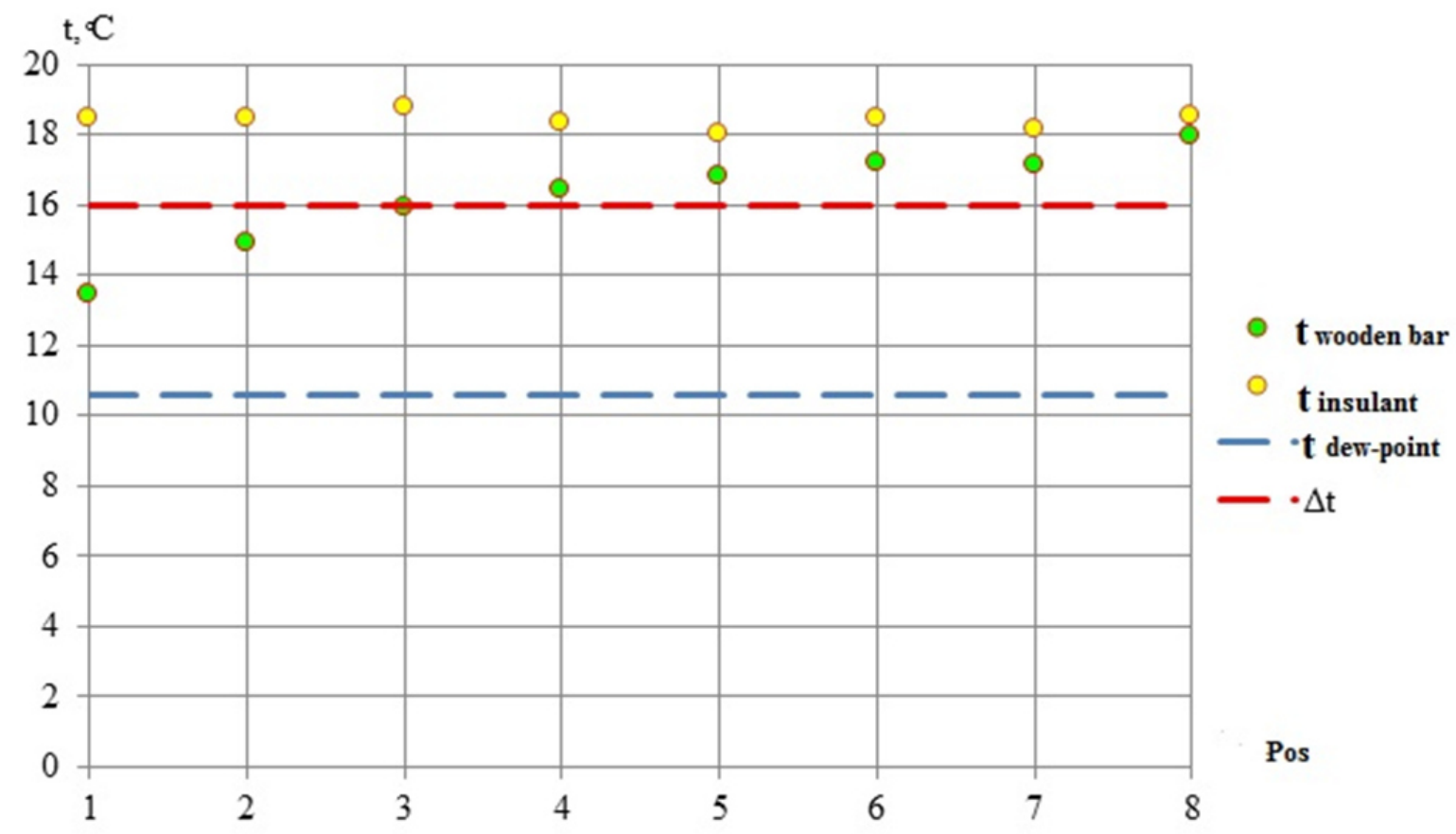

Figure 6. Graph of temperatures at the building envelopes surfaces

As seen from the graph, the optimal building envelope from thermal-technical part is construction 8, since this construction shows the most uniform temperature distribution on the inner surface, as well as compliance with the rated temperature differential between the indoor air temperature and the inner wall surface [4].

\section{Conclusion}

From all has been said it follows, that the applied construction of light building envelopes does not meet the requirements of thermotechnical standards. Thermotechnical calculation of such constructions should be made in the conditions of the extremely negative temperatures.

\section{References}

1. Bogoslovsky V.N. Building Thermophysics (thermophysical basics of heating, ventilation and air conditioning): Textbook for universities. - 2nd ed., Rev. and add. - M .: Higher. School, 1982. - p. 415, ill.

2. Ushkov F.V. Heat transfer of building envelopes when filtering air. - M .: Stroyizdat, 1969. - p.144.

3. GOST (All-Union State Standard) 26629-85 Buildings and constructions. Thermovision quality control method of building envelopes thermal insulation. - Moscow.: Publishing house of standards, 1986. - p. 16.

4. SNIP (Construction Rules and Regulations) 23-02-2003 Thermal protection of buildings. - M .: Gosstroy of Russia, FGUP TsPP (Federal State Unitary Enterprise, Centre of Construction Design Products), 2004. - p. 30.

5. GOST (All-Union State Standard) 26254-84 Buildings and constructions. Methods for determination of building envelopes thermal resistance. - Moscow.: Publishing house of standards, 1985. - p. 28.

6. Franchuk A.U. Tables of building materials thermotechnical characteristics, M.: Research Institute for Building Physics, 1969 - p. 142. 